\title{
Developing a theory of family care during critical illness
}

\author{
J de Beer, ${ }^{1,2}$ PhD; OrcID 0000-0001-6258-1603; P Brysiewicz, ${ }^{1}$ PhD; OrcID 0000-0002-6980-6710 \\ ${ }^{1}$ Discipline of Nursing, School of Nursing and Public Health, University of KwaZulu-Natal, Durban, South Africa \\ ${ }^{2}$ College of Nursing-Jeddah, King Saud bin Abdul-Aziz University for Health Sciences, Kingdom of Saudi-Arabia
}

Corresponding author: J de Beer (beerje@ngha.med.sa)

\begin{abstract}
Background. The critical illness of a loved one can negatively affect all family members (FMs), leading to the interruption of family functioning and integrity. Hospitalisation is a stressful, unplanned event for both the patient and FMs and is associated with psychological disturbances, emotional distress and altered family roles and functioning.

Objective. To develop a theory of family care in critical care units (CCUs) for the South African setting.

Methods. Grounded theory, based on Strauss and Corbin's school of thought, was used. Audio-recorded in-depth interviews were conducted with

32 participants (9 FMs, 17 critical care nurses and 6 doctors) at a private hospital (3 CCUs) and a state hospital (10 CCUs). Data analysis involved open, axial and selective coding.

Results. The theory of family care during critical illness was identified. The core concept of the theory is empowerment, informed by the underlying constructs of information sharing, proximity, garnering resources, and cultural and religious cooperation.

Conclusion. The concepts of this theory can equip healthcare professionals in CCUs to provide appropriate family care for meeting the needs of patients' FMs and, in so doing, contribute to families having a more manageable critical care experience during the illness of their loved one. Keywords. Critical care unit (CCU), family care, family members, grounded theory.
\end{abstract}

S Afr J Crit Care 2019;35(1):19-24. https://doi.org/10.7196/SAJCC.2019.v35i1.388

\section{Contribution of Study}

- This study adds to the limited body of knowledge regarding family care within the South African context. The study provides a theory to promote therapeutic partnerships between health care professionals, patients and FMs that will provide support for both the patient and FMs.

- It is further anticipated that the findings of the study will contribute not only to nurses' critical care curriculum, which currently includes very limited family support content, but also be helpful to doctors working in intensive care units.

Critical illness of a loved one and subsequent admission into the critical care unit (CCU) have notable effects on family members (FMs). Many studies have acknowledged the importance of identifying the needs of FMs during this difficult period in an attempt to ease the effects of this crisis. $^{[1-4]}$ Molter's seminal work ${ }^{[5]}$ that explored the needs of FMs led to the development of the Critical Care Family Needs Inventory, which categorises family needs into five domains, namely assurance, proximity, comfort, support and information. ${ }^{[6]}$

The admission of a loved one into the CCU may result in FMs experiencing symptoms of a psychological nature, both during and after the critical illness, such as generalised anxiety and depression, acute stress and post-traumatic stress. ${ }^{[7]}$ A survey by Lemiale et al. ${ }^{[8]}$ showed that $36 \%$ of FMs of patients admitted to the CCU were taking antidepressants or anxiolytic drugs, with $8 \%$ of FMs using psychotropic drugs after the discharge or death of a loved one. In addition, Pochard et al. ${ }^{[9]}$ who conducted a study among 544 FMs using the Hospital Anxiety and Depression Scale, found that depression and anxiety were evident in $73.4 \%$ and $35.3 \%$ of respondents, respectively. Presently, more attention is being directed towards family nursing in the critical care setting worldwide. ${ }^{[10]}$ Current family-centred interventions in CCUs include improving care that focuses on quality of life, symptoms of psychological distress and end-of-life care. ${ }^{[11]}$

The situation is complicated in resource-constrained settings such as South Africa (SA). SA's healthcare system comprises private (medical insurance) and state health sectors, with the focus on service delivery evolving from a curative, hospital-based service to a comprehensive primary healthcare approach. This redistribution of resources to primary healthcare has led to reduced resources being available for critical care. ${ }^{[12]}$ Although the state health sector has become a comprehensive, integrated national service, failure in leadership and stewardship and poor management have led to a struggle in handling major challenges associated with issues such as effective and efficient management of human resources, moonlighting, and ill discipline and absenteeism among staff. There has also been a tendency to retain incompetent staff or managers, and as a result 'loyalty rather than ability to deliver' has been rewarded for many years, with no climate of accountability. ${ }^{[13]}$

The CCU admission profile in SA is different from that of international CCUs. The majority of patients are typically male (65\%) and traumatic injuries (motor vehicle accidents, gunshots and stabbings) account for a large part (53\%) of admissions. The remainder comprises 
medical conditions such as sepsis, metabolic issues and overdose (30\%), post-surgical complications (4\%), gynaecological ailments (5\%) and infectious diseases (8\%). Mortality in CCUs in SA is $31.5 \% .^{[12]}$ According to Dondorp et al. ${ }^{[14]}$ sepsis and serious infections are more prominent in developing countries (e.g. 29\% in South Asia and 56\% in sub-Saharan Africa) than in higher-income countries (6\%). The South African Surgical Outcomes Study, ${ }^{[15]}$ conducted in 50 state hospitals, established that $56.5 \%$ of admissions were planned whereas the remainder were unplanned. Planned admissions were linked to a $34.5 \%$ incidence of infection (suspected or confirmed at the time of admission), with a higher incidence in unplanned admissions. In addition, diagnoses in unplanned admissions required more ventilator, renal and inotropic support in the first 48 hours after admission, notably longer stays in the CCU and higher overall mortality.

The HIV/AIDS pandemic also has a profound effect on CCUs in SA. From a total population of 56.52 million people, 7.1 million are living with HIV infection, ${ }^{[16]}$ which increases the strain on these healthcare services. In addition, $16 \%$ of the nursing profession is affected by HIV/ AIDS. ${ }^{[12]}$ Despite SA having a sophisticated healthcare structure in some areas, the disease profile reflects that of a less-developed world. ${ }^{[17]}$

As no documented family care programmes or interventions are currently available in SA, there is limited support to foster a positive change with regard to family support in CCUs. Despite international models and theories of family care being available, it may be difficult to apply these to the unique SA context of critical care, compounded by SA being a multicultural society. The aim of the study was therefore to develop a theory of family care in CCUs for the SA setting.

\section{Methods \\ Research design}

This study followed a grounded theory approach based on Strauss and Corbin's paradigm model, ${ }^{[18]}$ which provided some detail and structure regarding data analysis and allowed for the development of a theory. The grounded theory approach is further also suitable in areas where limited research has been conducted, as is the case with research on family care in CCUs in SA. ${ }^{[18,19]}$ Epistemologically, the researcher worked on the assumptions that the world consists of multiple individual realities influenced by context; ontologically, reality was viewed as being subjective and multiple. The researcher's axiological approach was that all research is value laden and that biases are present. ${ }^{[20]}$

\section{Research setting}

The CCUs of two hospitals in the eThekwini metropolitan area, KwaZulu-Natal, were selected. Hospital A is a public tertiary referral hospital and relies on public-private partnership for service delivery. It consists of 807 beds and has 10 CCUs. Hospital B is a 400-bed private hospital that forms part of one of the largest private hospital groups in SA. This hospital has three CCUs, focusing on surgical, cardiac and general critical care cases. The researcher used a mix of private and public CCUs, as FMs, critical care nurses (CCNs) and doctors may face different challenges in the private and public sectors. All CCUs from the two hospitals were included in the study.

\section{Study participants}

The study participants included doctors, CCNs and the FMs of patients admitted to the selected CCUs. An initial sample of three participants from each site was used and sampling continued until data saturation was reached, resulting in a total of 32 participants. All doctors and CCNs who had at least 6 months' experience working in a critical care context and FMs who had had a loved one admitted to a CCU for at least 24 hours were eligible for inclusion in the study. Participants were included based on their availability and willingness to participate at the time of data collection.

\section{Data collection}

Data were collected by the researcher during in-depth interviews. At the start of an interview, the researcher informed the participant of the nature of the study and the associated ethical considerations. FM interviews started with two primary questions: (i) 'Tell me about your relationship with the patient' and (ii) 'Tell me about your experience of having a loved one admitted to the critical care unit.' Interviews with CCNs and doctors started with the following question: 'Tell me about your experiences of dealing with family members.' These primary questions were followed with further probes. Interviews were conducted in a private space in the respective CCUs and lasted $30-45$ minutes. All interviews were audio recorded. Data collection spanned a period of 6 months.

\section{Data analysis}

Data analysis involved the characteristic coding phases of grounded theory (open, axial and selective coding) suggested by Strauss and Corbin ${ }^{[21]}$ During open coding, the data were segmented into meaningful expressions and described using single words or phrases. These were then analysed to form categories that could be developed further, based on attributes or characteristics (Fig. 1).

The initial open coding was followed by axial coding, which involved looking for relationships between the identified categories, as suggested by the paradigm model of the grounded theory approach. ${ }^{[18]}$ Categories were grouped under specific headings and analysed further with regard to their properties (Fig. 2)

The final phase - selective coding - involved integrating and linking the main categories into a conceptual framework that represents the theory grounded in the data. A storyline had to be formulated to facilitate integration. The researcher moved from a descriptive storyline to a conceptual one, which meant that the central phenomenon had to be identified based on the categories that had been described.

The process of induction, deduction and validation was applied throughout data collection, ${ }^{[2]}$ as this allowed the researcher to verify the emerging theory.

\section{Academic rigour}

The following principles of academic rigour applied:

Credibility: Space triangulation was used to collect data on the same phenomenon from two sites (a private hospital and a state hospital) to test for cross-site consistency. ${ }^{[22]}$ Peer debriefing was used for external validation of the emerging data. Member checking was applied, as this was regarded as the most important technique for establishing credibility of the data in this study. ${ }^{[23]}$ This involved the researcher providing feedback about the emerging data and her interpretation to participants to ensure it was a true reflection of their reactions. The study participants did not suggest any changes.

Dependability: A dependability audit was performed. This involved an expert $\mathrm{CCN}$ reviewing the researcher's audio recordings, transcripts, 
$\mathrm{R}$ Ja
Verbalising no special relisious or cultural needs.

From having your husband in I.C.U and err and having this experience would you say to, how would you think the support they give to family members can improve. zrequesing more information sharing providing explanations

May be just by talking more to them make them understand that you, what is actually happening you know cos at the moment I want to know err how long is he going to be under such heavy sedation and you know, like all your question answered, I want to see requesting the I.C.U doctor had on call somewhere, so ja, phone him and say to him that faccess fo in fo Mrs.Pretorius would like to speak to you are or if you are not busy just err , I mean I am expressing working as well, even if you phone they are either in theatre, err they are very busy commitwent people you got to try and speak to them when you are here people you got to try and speak to them when you are here, I have been here a day or two Doction even the sisters try and help you and explain things to you. I want to hear what the doctor plans are, I want to know what is going to happen next week what are they planning. Is expectring he going to have another operation. What are they gonna operate on. I need to know fo question these things. These no one that can tell me anything. There's no doctor today, I could speak to the doctor yesterday, he was not available so I am basically in the dark. feeling It is very hard without that information

The thing is you have family members, phoning you from all over the country wanting to know what is happening and you say there is nothing, there is no change and they think feething. you are, you err, err, not asking questions, you not really worried about things but they helples don't understand that I don't have that information to pass onto them.

You've spent, actually you've spent same time here in the waiting area. Ciarrening of Err ja, maybe some water, so people can get up and have some water and replace the bottle that has disinfectant that was, they only replaced that on Friday and the whole week I felt jerky and it say please disinfectant you hand, but no one actually check on that, err and ja just like, ja it would be nice to, I know the nurse have to get around him,

Fig. 1. Initial codes identified during open coding.

Challengts
(t)

Fig. 2. Example of axial coding in process.

field notes and reflexive journal used during the study.
Confirmability: A confirmability trail was established by the researcher's recording the research activities during the study so that others can follow the research process.

Transferability: The researcher provided sufficiently thick descriptions by providing detailed descriptions of the research setting, participants, data collection methods and the timeframe of data collection. The researcher also recorded notes in a field journal, which contributed not only to establishing confidence in the data but also to ensuring the transferability of data.

\section{Ethical considerations}

Permission for the study was granted by the University of KwaZulu-Natal Ethics Committee (ref. no. HSS/0102/10) and the management of both the public and private hospitals. Written consent was obtained from all study participants. Owing to the sensitive nature of the topic, a psychologist was available for counselling should any participant have required this service during the interview process.

\section{Results \\ Sample realisation}

A total of nine FMs were interviewed (mean age: 31.5 years), with the majority $(89 \%)$ being women. The average length of patients' stay was 9 days. Participating healthcare professionals (HCPs) included $17 \mathrm{CCNs}$ (mean age 35 years) and 6 doctors (mean age 37 years). The work experience among doctors and CCNs ranged from 6 months to 20 years.

\section{The theory}

The emerging theory was called the "Theory of Family Care during Critical Illness' (Fig. 3). One core concept (empowerment) and four subconcepts (information sharing; proximity; garnering resources; cultural and religious cooperation) emerged.

\section{Core concept: Empowerment}

Empowerment refers to a transition process during which FMs move from powerlessness to improved personal capacity, enabling them to deal effectively with the emotional, cognitive, physical and environmental challenges associated with the critical illness of a loved one. HCPs assist FMs in mobilising resources (emotional, cognitive, physical and environmental) to adequately manage this crisis period. In this context, empowerment also refers to the empowerment of HCPs, who, in providing family care, interact and develop relationships with FMs and so acquire knowledge and skills that aid in adequately mobilising resources both for themselves and for FMs. 


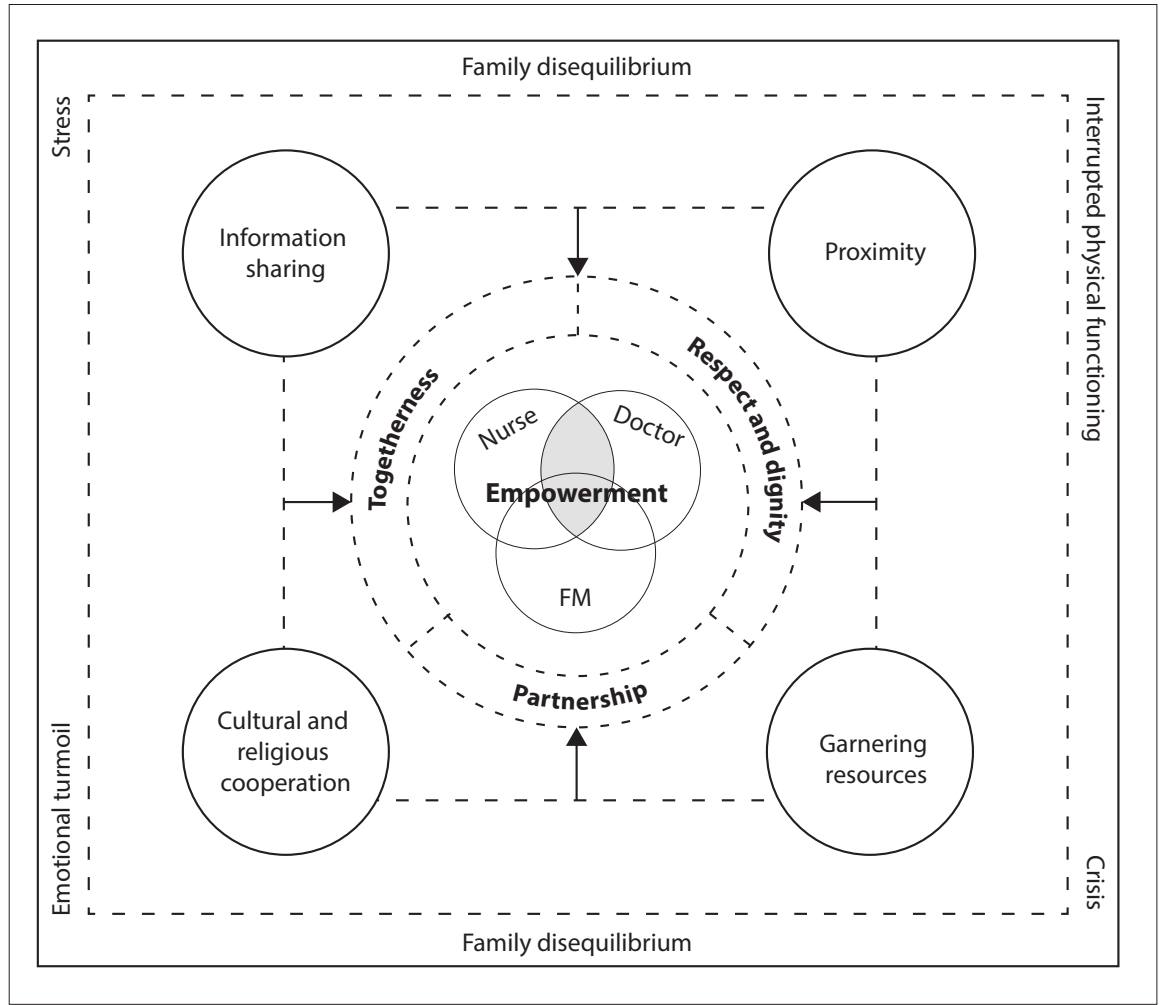

Fig. 3. Theory of family care during critical illness.

$F M=$ family member.

Empowerment is facilitated by information sharing, proximity, garnering resources, and cultural and religious cooperation.

\section{Subconcept 1: Information sharing}

Information sharing refers to the exchange of necessary data or facts about the critical illness between HCPs and FMs, which increases the knowledge base of both parties. When FMs receive information about the patient's condition, treatment, prognosis or outcome, their knowledge increases, enabling them to better deal with the critical illness of a loved one. Both Cypress ${ }^{[24]}$ and De Beer and Brysiewicz ${ }^{[4]}$ reported that sharing information contributes to psychosocial support of FMs and that providing information to FMs about the patient's care reduces anxiety associated with the unfamiliar critical care environment. Information regarding the technical milieu of critical care also forms a crucial component of information sharing, as illustrated in the following interview extracts:

'I needed information to be able to understand what's happening. To know what's happening could have helped me to manage the situation better. Without information, I was scared, stressed and panic stricken [ed].'- FM (patient's husband)

'They just need somebody to explain things to them. They come in and see their loved provide that support to the patient, and give the patient their love. This sometimes creates a source of hope for the patient and themselves, even if the patient is sedated or unconscious.' - Doctor

\section{Subconcept 3: Garnering resources}

Garnering resources refers to FMs acquiring resources for themselves, with reference to both material and non-material resources. Material resources refer to the comfort and nutrition needs of FMs. It is important for FMs to have adequate periods of rest and sleep. This can be encouraged by providing comfortable couches in the waiting area or if possible, a designated area that has been made homely and comfortable. Jamerson et al. ${ }^{[27]}$ suggest that because FMs often feel they need to stay near the CCU, it is important to provide ready access to fluids and nutrition (e.g. coffee stations and vending machines) in the waiting area. This concept was described as follows by participants:

'We need to have comfortable seating arrangements for FMs in the waiting area as they spend many hours in there. Sometimes we try and accommodate FMs [who] are travelling [from] far.' - CCN

ones with a tube in their mouth or nose, not responding, and a whole lot of drugs. And even if the patient is getting better... it is the first thing that they are seeing, the patient. They think the worst, and they get very emotional, so you need someone to explain to them.' - Doctor

\section{Subconcept 2: Proximity}

Proximity refers to being flexible with regard to the family's access to the patient and making it easier for them to be (physically and psychologically) close to their loved one. Such closeness allows FMs to monitor the situation, track the care given to the patient and develop trust and confidence in the care. This is supported by Plakas et al. ${ }^{[25]}$ and also Fateel and O'Neill, ${ }^{[26]}$ who reported that FMs felt a strong need to be close to the patient to see what was going on. When FMs are unable to maintain closeness to their loved one, the resulting lack of reassurance fuels negative emotions such as fear, anxiety and helplessness. Allowing FMs to be close to the patient reduces these negative emotions as they are able to provide support to the patient without a loss of intimacy. Closer proximity is therefore regarded as beneficial to both the patient and the FMs. This was explained by a participant as follows:

'They also need to be given the opportunity to be closer to the patient, to be able to
'Maybe also getting something like, you know, like a "lazy boy", especially when people come to [the] ICU. There are people [who] come from far and you know that they need to be comfortable. They do wait in the waiting room, but it's like normal chairs. Maybe they should think about things like that: a comfortable environment where people can be comfortable waiting for many hours.' - FM (patient's mother)

The non-material dimension relates to maintaining hope. McKiernan and McCarthy ${ }^{[28]}$ found that FMs used a sense of hope as reassurance, irrespective of the diagnosis of the patient. Participants expressed that hope was necessary to cope with the situation. Non-material resources also include FMs' sharing feelings of suffering with others, such as family, friends or HCPs. This was described by a patient's daughter as follows:

'The staff was [sic] quite warm. The sisters are quite happy to give you a hug and ask you if you need anything, and that's what you need: you need that human touch. It is like the staff are able to put themselves in our shoes and know what we are going through.' - FM (patient's daughter) 


\section{Subconcept 4: Cultural and religious cooperation}

The concept of cultural and religious cooperation refers to HCPs displaying a sense of awareness, respect, understanding and acceptance of the attitudes, values, beliefs and practices of FMs during the critical illness of a loved one. The patient and FMs are recognised as individuals in a cultural and religious context, and care by HCPs should be aimed at being culturally and religiously congruent. HCPs should further also be aware of their own cultural biases and prejudices and ensure that they do not impose these on either the patient or a FM, as it could lead to situations of cultural, religious or professional conflict. Cook and Rocker ${ }^{[29]}$ stated that cultivating culturally and spiritually sensitive care is an essential component of critical care, especially in cases of palliative care. According to these authors, the meaning assigned to critical illness, especially when death is inevitable, is frequently interpreted through a spiritual lens: 'For many people, critical illness triggers existential questions about purpose (of life, death, and suffering), relationships (past, present, and future), and destiny. ${ }^{[29]}$ The importance of cultural and religious cooperation was mentioned by participants in the study:

'Well, you've got to have a basic understanding of the different cultures, and what is acceptable and what is not acceptable in that cultural group. For example, giving a patient who's a Jehovah's Witness blood, is unacceptable, so you've got to understand what's acceptable and what's not acceptable. Whether you agree with it or not is not the point; it's beside the point. But you've got to respect the ... basically their point.' - CCN

'There were religious things that I needed to do, but they [the HCPs] did not stop us in any way. They allowed us the opportunity to do what we had to do. Like when it was my boy's last rites ... I think they should allow us, the family, to do what we have to do.' - FM (patient's mother)

\section{Discussion \\ Description of the theory}

Fig. 3 is a diagrammatic representation of the described theory. It illustrates that crisis and stress associated with the extreme illness of a loved one lead to a state of disequilibrium, which manifests as emotional turmoil and interrupted physical functioning among FMs. Family disequilibrium is mitigated by HCPs allowing FMs access to the patient, sharing information about the patient with the family, assisting FMs in accessing resources and support, and being cognisant of the cultural and religious customs and beliefs of FMs. These factors empower not only the FMs, but also the HCPs. This process is facilitated by the HCPs, who, in allowing time to engage with a patient's family, create a perception of partnership. This interaction suggests respect for the person and the situation and contributes to FMs feeling dignified.

\section{Assumptions of the theory}

The following assumptions support the identified theory of family care during critical illness:

- Family care is a collaborative effort. CCNs, doctors and FMs all have key roles and there is an inextricable link between them in providing family care in the critical-care environment.

- Family care builds on the strength and connectedness of the family; the family is viewed as a unit rather than as individuals.

- Family care requires a shift in institutional practices and moving from the model of the HCP having expert knowledge to one that facilitates knowledge exchange.
- The highly technical environment of the CCU is stressful for both HCPs and FMs, resulting in their expending considerable time and energy to cope during periods of uncertainty and fear.

- Family care leads to therapeutic relationships developing between HCPs and FMs, which foster trust.

- Family care promotes an awareness of caring in a multicultural context.

\section{Context of the theory}

The theory developed in this study is an explanatory approach to the process of family care in CCUs in the SA context, which is characterised by a diverse multicultural sociopolitical system. The context of the theory refers to the technical milieu of the CCU, which is sometimes perceived as a 'hostile' environment characterised by highly technical equipment, bright lights, unexpected noise, restricted visiting allowances and a rushed pace, with constant activities aimed at saving the lives of critically ill patients. The sudden critically ill state of the patient, coupled with the technical environment of the $\mathrm{CCU}$, creates the physical context for the theory. However, Strauss and Corbin ${ }^{[18]}$ refer to a context as not necessarily being only the physical environment, but rather a particular set of conditions in which interactions take place to manage, handle, perform and respond to a specific occurrence. The context of this theory, therefore, also encompasses family disequilibrium, which consists of emotional turmoil, interrupted physical functioning, stress and crisis.

\section{Purpose of the theory}

According to Chinn and Kramer, ${ }^{[30]}$ the purpose of a theory is important because it specifies the context and situations in which it applies. The theory developed in this study provides knowledge of and insight into family care, and its overall purpose is to enhance family care during the critical illness of a loved one. It will equip HCPs with information to encourage their shifting from a biomedical model of care to one that focuses on caring for the patient within a family context, with the family seen as part of the health team. The family is recognised as having expertise that, in collaboration with the healthcare team, contributes towards achieving the best possible outcome for the patient and individual FMs. As the SA health sector is so culturally diverse, one of the goals of the theory is to enhance family care through the integration of culture-specific healthcare and incorporating the principles of $u b u n t u$ (solidarity and partnership), a concept that is somewhat unique to the people of this country.

Another purpose of the theory is directly related to the concept of empowerment, as both FMs and HCPs can equip them with the resources (physical and psychological) to deal effectively with the critical illness of a patient. Such empowerment is based on the premise that these role players will build on their respective strengths rather than their weaknesses. The concepts of this theory further add to the process of empowerment by encouraging practices in the healthcare setting that are aimed at empowerment. Although the theory was developed in the context of critical care, it is not restricted to this area. The concepts are broad enough to be applied to other disciplines of healthcare in which the empowerment of FMs and HCPs is a goal.

\section{Evaluation of the theory}

The theory was evaluated based on whether it was: (i) fitting; (ii) understandable; (iii) general; and (iv) controlled. ${ }^{[31]}$

The theory was regarded as fitting owing to the essential information used to describe the characteristics of FMs and HCPs and the context 
used in the study. Information regarding the CCUs included in the study was also provided. The fittingness of the study was further demonstrated by relating each category of the theory to literature to highlight possible similarities or differences between current research and that of earlier theoretical constructs. However, despite efforts to ensure fittingness, the 'final judgement of the transferability of the findings ultimately rests with the reader. ${ }^{[31]}$

To ensure that the phenomenon investigated is accurately identified and delineated, study participants should guide the enquiry process. In the context of the present study, participants' responses were used to guide further data collection. For example, when participants were asked to conceptualise family care; they used words such as 'partnership', 'togetherness', 'humanity' and 'collaboration'. These words subsequently became codes that directed further enquiry and interview questions (for example: 'What do you mean by family care being defined as humanity?') In addition, two participants, a HCP and a FM, were asked to review the final diagrammatic presentation of the theory and its descriptions. They indicated that the theory accurately represented their experiences and meaning of family care during critical illness in the critical care setting.

The researcher strove for generality by writing conceptually about the concepts and subconcepts of the theory, rather than simply offering descriptions. However, despite in-depth descriptions being provided, it is ultimately up to the reader to decide whether the suggested theory can be applied to other settings.

Control was achieved by using the paradigm model during data analysis. Causal, facilitative and inhibitive intervening conditions are all components of the paradigm model.

\section{Study limitations}

This study setting was confined to an urban setting and thus a rural setting was not taken into account. Although the findings of qualitative research are usually not generalisable to the larger population, having excluded a rural setting may mean that the findings reflect only the experiences of FMs and HCPs in an urban setting and that the experiences of FMs and HCPs in a rural setting may be different. Furthermore, as the setting was confined to a single province (KwaZuluNatal), the cultural dynamics may not be representative of those in other SA provinces. The cultural findings of this study may therefore be geographically limited. The majority of the FMs interviewed were female, and consequently the findings represent mostly the experiences of women.

\section{Conclusion}

This study put forward a substantive middle-range theory that has been grounded in data collected from HCPs and FMs. The theory identifies family care as a collaborative effort between HCPs and FMs, characterised by partnership and trust. In addition, this theory allows for family care to be positioned in a culturally diverse context. The constructs of this theory equip HCPs in CCUs to provide appropriate family care to meet the needs of FMs and, in doing so, contributing to a more manageable and less stressful critical care experience for patients' families. The recommendations include implementing and evaluating the theory. Further research needs to be conducted in rural settings in $\mathrm{SA}$, where the issue of limited resources is more prominent.
Author contributions. JdB and PB contributed equally to all aspects of the study.

Funding. Funding from the National Research Foundation is acknowledged. Conflicts of interest. None.

1. Daley L. The perceived immediate needs of families with relatives in the intensive care setting. Heart Lung 1984;13(3):231-237.

2. Leske JS. Needs of adult family members after critical illness: Prescriptions for interventions. Crit Care Nurs Clin North Am 1992;4(4):587-596. https://doi.org/10.1016/S0899-5885(18)30606-3

3. Azoulay E, Pochard F, Kentish-Barnes N, et al. Risk of post-traumatic stress symptoms in family members of intensive care unit patients. Am J Respir Crit Care Med 2005;171(9):987-994. https:/ doi.org/10.1164/rccm.200409-1295OC

4. De Beer J, Brysiewicz P. The conceptualization of family care during critical illness in KwaZulu-Natal, South Africa. Health SA Gesondheid 2017;22(1):20-27. https://doi.org/10.1016/j. hsag.2016.01.006

5. Molter NC. Needs of relatives of critically ill patients: A descriptive study. Heart Lung 1979;8(2):332-339.

6. Leske JS. Internal psychometric properties of the Critical Care Family Needs Inventory. Heart Lung 1991;20(3):236-244.

7. Gerritsen RT, Hartog CS, Curtis JR. New developments in the provision of family-centered care in the intensive care unit. Intensive Care Med 2017;43(4):550-553. https://doi.org/10.1007/ S00134-017-4684-5

8. Lemiale V, Kentish-Barnes N, Chaize M, et al. Health-related quality of life in family members of intensive care unit patients. J Palliat Med 2010;13(9):1131-1137. https://doi.org/10.1089/ jpm.2010.0109

9. Pochard F, Azoulay E, Chevret S, et al. Symptoms of anxiety and depression in family members of intensive care unit patients: Ethical hypothesis regarding decision-making capacity. Crit Care Med 2001;29(10):1893-1897. https://doi.org/10.1097/00003246-200110000-00007

10. Svavarsdottir EK, Sigurdardottir AO, Konradsdottir E, et al. The process of translating family nursing knowledge into clinical practice. J Nurs Scholarsh 2015;47(1):5-15. https://doi. org/10.1111/jnu. 12108

11. Long AC, Kross EK, Curtis JR. Family-centered outcomes during and after critical illness: Current outcomes and opportunities for future investigation. Curr Opin Crit Care 2016;22(6):613-620. https://doi.org/10.1097/MCC.0000000000000360

12. De Beer J, Brysiewicz P, Bhengu BR. Intensive care nursing in South Africa. S Afr J Crit Care 2011;27(1):6-10

13. Coovadia H, Jewkes R, Barron P, Sanders D, McIntyre D. The health and health system of South Africa: Historical roots of current public health challenges. Lancet 2009;374(9692):817-834. https://doi.org/10.1016/S0140-6736(09)60951-X

14. Dondorp AM, Iyer SS, Schultz MJ. Critical care in resource-restricted settings. JAMA 2016;315(8):753-754. https://doi.org/10.1001/jama.2016.0976

15. Skinner DL, De Vasconcellos K, Wise R, et al. Critical care admission of South African (SA) surgical patients: Results of the SA Surgical Outcomes Study. S Afr Med J 2017;107(5):411-419. https://doi.org/10.7196/SAMJ.2017.V107i5.11455

16. Statistics South Africa. 2017. Mid-year population estimates. https://www.statssa.gov.za/ publications/P0302/P03022017.pdf (accessed 18 February 2019).

17. Mathivha LR. ICUs worldwide: An overview of critical care medicine in South Africa. Crit Care 2002;6(1):22-23. https://doi.org/10.1186/cc1449

18. Strauss A, Corbin J. Basics of Qualitative Research. Grounded Theory Procedures and Techniques. Newbury Park: Sage, 1990.

19. Lawrence J, Tar U. The use of grounded theory technique as a practical tool for qualitative data collection and analysis. Electron J Bus Res Methods 2013;11(1):29.

20. Crotty M. The Foundations of Social Research. London: Sage, 1998.

21. Strauss A, Corbin J. Basics of Qualitative Research: Grounded Theory Procedures and Techniques. 2nd ed. Newbury Park: Sage, 1998.

22. Polit DF, Beck CT. Nursing Research: Generating and Assessing Evidence for Nursing Practice. 8th ed. Philadelphia: JB Lippincott, 2012.

23. Lincoln Y, Guba E. Naturalistic Inquiry. Newbury Park: Sage, 1985

24. Cypress BS. The lived ICU experience of nurses, patients and family members: A phenomenological study with Merleau-Pontian perspective. Intensive Crit Care Nurs 2011;27(5):273-280. https://doi org/10.1016/j.iccn.2011.08.001

25. Plakas S, Cant B, Taket A. The experiences of families of critically ill patients in Greece: A social constructionist grounded theory study. Intensive Crit Care Nurs 2009;25(1):10-20. https://doi. org/10.1016/j.iccn.2008.04.003

26. Fateel EE, O'Neill CS. Family members' involvement in the care of critically ill patients in two intensive care units in an acute hospital in Bahrain: The experiences and perspectives of family members' and nurses' - A qualitative study. Clin Nurs Stud 2016;4(1):57-69. https://doi. org/10.5430/cns.v4nlp57

27. Jamerson PA, Scheibmeir M, Bott MJ, Crighton F, Hinton RH, Cobb AK. The experiences of families with a relative in the intensive care unit. Heart Lung 1996;25(6):467-474. https://doi. org/10.1016/s0147-9563(96)80049-5

28. McKiernan M, McCarthy G. Family members' lived experience in the intensive care unit: A phemenological study. Intensive Crit Care Nurs 2010;26(5):254-261. https://oi.org/10.1016/j. iccn.2010.06.004

29. Cook D, Rocker G. Dying with dignity in the intensive care unit. N Engl J Med 2014;370(26):25062514. https://doi.org/10.1056/NEJMra1208795

30. Chinn P, Kramer M. Integrated Theory and Knowledge Development in Nursing. St Louis: Mosby, 2008.

31. Chiovitti RF, Piran N. Rigour and grounded theory research. J Adv Nurs 2003;44(4):427-435. https://doi.org/10.1046/j.0309-2402.2003.02822.x 